\title{
Level Berpikir Pertanyaan Guru pada Pembelajaran Bahasa Indonesia
}

\section{Thinking Ability of Teacher Questions on Indonesian Language Learning}

\author{
Andi Rurisfiani ${ }^{1}$; Ramly'; Sultan ${ }^{3}$
}

Artikel diterima editor tanggal 25-03-2019, disetujui untuk dipublikasikan tanggal 12-04-2019 Doi: https://doi.org/10.26499/bahasa.v1i2.37

\begin{abstract}
Abstrak
Analisis Pertanyaan Guru dengan Kerangka LOTS (Lower Order Thinking Skills) dan HOTS (Highter Order Thinking Skills) pada Pembelajaran Bahasa Indonesia di SMKN 3 Soppeng. Penelitian ini bertujuan mendeskripsikan wujud pertanyaan LOTS dan HOTS guru pada awal, tengah, dan akhir pembelajaran Bahasa Indonesia di SMK Negeri 3 Soppeng dengan menggunakan panduan Taksonomi Bloom Revisi Anderson \& Krathwohl. Analisis dalam penelitian ini merupakan penelitian deskriptif kuantitatif. Teknik yang digunakan dalam pengumpulan data adalah teknik rekam dan teknik catat. Teknik yang digunakan untuk menganalisis data dalam penelitian ini adalah statistik deskriptif. Hasil penelitian menunjukkan bahwa pada awal dan akhir pembelajaran terdapat $100 \%$ pertanyaan tingkat rendah (LOTS). Pada inti pembelajaran sebanyak $89.72 \%$ pertanyaan tingkat rendah dan sebanyak $10.28 \%$ pertanyaan yang termasuk kategori pertanyaan tingkat tinggi (HOTS).
\end{abstract}

Kata kunci:pertanyaan guru, LOTS, HOTS, interaksi pembelajaran

\section{Abstract}

Analysis of Teacher Questions with the Framework of LOTS (Lower Order Thinking Skills) and HOTS (High Order Thinking Skills) on Indonesian Language Learning in Soppeng Vocational High School 3. This study aims to describe the form of LOTS and HOTS teacher questions at the beginning, middle, and end of Indonesian Language learning at Soppeng State Vocational High School 3 using the Bloomers \& Anderson Revision Taxonomy guide. The analysis in this study is a quantitative descriptive study. The techniques used in data collection are record and technique notes. The technique used to analyze data in this study is descriptive statistics. The results of the study indicate that at the beginning and end of learning there are 100\% low-level questions (LOTS). At the core of learning, $89.72 \%$ of low-level questions and as many as $10.28 \%$ of questions belong to the category of high-level questions (HOTS).

Keywords: teacher questions, LOTS, HOTS, learning interactions

\footnotetext{
${ }^{1}$ Andi Rurisfiani, Universitas Negeri Makassar, andirurisfiani28@gmail.com

${ }^{2}$ Ramly, Universitas Negeri Makassar, ramly@unm.ac.id

${ }^{3}$ Sultan, Universitas Negeri Makassar, sultan@unm.ac.id
} 


\section{Pendahuluan}

Interaksi belajar mengajar antara siswa dengan guru sangat penting bagi proses pembelajaran. Komunikasi harus berjalan dengan baik demi ketercapaian tujuan pembelajaran.Agar terjadi komunikasi yang baik antara pendidik dan peserta didik, guru harus mampu membangun stimulus terhadap peserta didik sehingga mereka mampu mengeluarkan pendapatanya masing-masing. Pendidik harus menciptakan iklim belajar yang baik dan menyenangkan pada proses pembelajaran agar siswa dapat terlatih untuk berpikir kreatif, inovatif, dan kritis. Keterampilan berpikir kritis seseorang dapat dikembangkan melalui proses pembelajaran.

Menurut Uswana (dalam Astuti dkk, 2013) kemampuan untuk mengekspresikan, mengeluarkan pendapat, membuat keputusan, dan kemampuan untuk memberikan penilaian termasuk ke dalam aspek berpikir kritis. Kemampuan berpikir dan bernalar pada proses pembelajaran sangatlah diperlukan, baik untuk menjawab pertanyaan-pertanyaan yang diajukan oleh guru maupun memecahkan masalah-masalah yang terjadi pada proses pembelajaran.Di era milenial sekarang ini, kemampuan berpikir kritis sangatlah diperlukan.

Hasil studi International Reading Assesment (IRA) melalui Progress in International Reading Literacy Studi (PIRLS) menunjukkan kelemahan proses pembelajaran berpikir kritis di Indonesia yang berada di bawah skor rata-rata. Pada tahun 2006 skor yang diperoleh sebanyak 407. Namun demikian, pada tahun 2013 mengalami peningkatan dengan skor sebanyak 428. Hal tersebut masih dikategorikan berada di bawah rata-rata karena skor ideal pada tes Progress in International Reading Literacy Studi(PIRLS) yaitu 500 skor (Sultan, 2017).

Sebagai seorang pendidik yang baik, seharusnya proses berpikir kritis diajarkan sejak dini. Ennis, Marin, dan Halpen (dalam Astuti, dkk, 2017) menjelaskan bahwa salah satu indikator yang dapat menyebabkan seseorang mampu berpikir kritis yaitu pertanyaan atau argumen yang muncul di dalam sebuah proses pembelajaran.

Seorang guru tidak boleh mengabaikan pertanyaan yang diajukan kepada siswanya. Guru harus perlu memilih pertanyaan-pertanyaan yang berkualitas untuk melatih pemahaman dan ketangkasan siswa untuk bernalar dan berpikir kritis.Rosenshine (dalam Brown, 1984)mengemukakan bahwa teknik bertanya guru ketika melaksanakan proses pembelajaran mempunyai pengaruh terhadap pencapaian belajar dan cara berpikir siswa (Widjaya, dkk, 2013).

Untuk melatih tingkat berpikir kritis peserta didik, pertanyaan yang seharusnya muncul, yaitu pertanyaan yang melatih untuk mengekspresikanpemikiran, mengeluarkan pendapat, membuat keputusan, kemampuan untuk memberikan penilaian dan perbandingan (Astuti dkk, 2017). Seorang pendidik harus terampil memilih dan mengajukan sebuah pertanyaan kepada peserta didiknya karena hal tersebut merupakan hal yang sangat penting bagi ketercapaian sebuah tujuan pembelajaran (Hamzah \& Sultan: 2014).

Pembelajaran yang lebih mengembangkan proses berpikir tingkat tinggi termasuk dalam kategori High Order Thinking Skills (HOTS) dan sebaliknya pembelajaran yang mengembangkan proses berpikir tingkat rendah termasuk dalam kategori Lower Order Thinking Skills (LOTS) (Astuti, dkk. 2107). HOTS didasarkan pada konten, kritis, dan berpikir kritis, sedangkanLOTS menunjukkan masih rendahnya tingkat berpikir peserta didik. Jika masih di dalam tataran mengigat dan memahami, maka termasuk LOTS. 
JURNALBAHASA

2019, Vol 1(No 2), hlm. 111 - 119

https://jurnal.ppjb-sip.id/index.php/bahasa

E-ISSN:

LOTS dan HOTS dapat diklasifikasikan berdasarkan Taksonomi Bloom revisi ranah kognitif, yaitu C1 mengingat (remembering), C2 memahami (understanding), C3 menerapkan (applying), C4 menganalisis (analizying), C5 mengevaluasi (evaluating), dan C6 mencipta (creating). Dalam penelitian ini, C1 mengingat (remembering), C2 memahami (understanding), C3 menerapkan (applying) dikategorikan sebagai berpikir tingkat rendah (LOTS).Sedangkan C4 menganalisis (analizying), C5 mengevaluasi (evaluating), dan C6 mencipta (creating) termasuk dalam kategori berpikir tingkat tinggi (HOTS)(Anderson \& Krathwohl, 2001:6).

Penelitian ini akan dilaksanakan di SMK Negeri 3 Soppeng. Berdasarkan hasil pengamatan, siswa-siswa yang terdapat di sekolah ini belum mampu berbicara di depan umum. Apalagi dalam sekolah kejuruan, siswa diharapkan mampu mengembangkan proses berpikir kreatif untuk ketercapaian tujuan pembelajarannya. Karena pada sekolah kejuruan sangat mengutamakan kompetensi atau keterampilan siswa dalam mengerjakan sesuatu.

\section{Metode Penelitian}

Penelitian ini termasuk jenis penelitian jenis penelitian deskriptif dengan desain penelitian kualitatif-kuantitatif.Populasi dalam penelitian ini adalah semua pertanyaan yang diajukan guru selama mengajar di SMKN 3 Sopppeng. Sampelnya yaitu pertanyaan yang diajukan guru setiaplima kali proses pembelajaran bahasa Indonesia di SMKN 3 Soppeng.

Instrumen utama dalam penelitian ini adalah pedoman analisis isi yaitu nstrumen panduan analisis data berisi nomor, keterampilan berpikir, proses kognitif, dan sub aspek.Teknik yang digunakan untuk mengumpulkan data dalam penelitian ini yaitu teknik rekam dan catat.

Teknik yang digunakan untuk menganalisis data dalam penelitian ini adalah statistik deskriptif.Adapun cara menganalisis datanya yaitu mendeskripsikan data sehingga tergambar wujud pertanyanyaan sesuai dengan Taksonomi Bloom Revisi Anderson dan Krathwohl, yaitu ranah proses kognitif ada enam macam.

\section{Hasil Dan Pembahasan}

\section{Hasil}

Pemaparan hasil penelitian ini ditulis berdasarkan berdasarkan wujud pertanyaan LOTS dan HOTS guru pada awal, tengah, dan akhir pembelajaran. Hasil penelitian secara umum menunjukkan bahwa pada awal pembelajaran, guru tidak pernah mengajukan pertanyaan tingkat tinggi (HOTS), pada inti pembelajaran, guru hanya sesekali pengajukan pertanyaan tingkat tinggi, dan pada akhir pembelajaran, guru kembali tidak pernah mengajukan pertanyaan tingkat tinggi. Pemaparan hasil penelitian dapat dilihat pada tabel berikut:

Tabel 1. Jumlah Pertanyaan Guru pada Awal Pembelajaran

\begin{tabular}{cllll}
\hline Ket. Berpikir & Proses Kognitif & \multicolumn{1}{c}{ Sub Aspek } & Frekuensi & Persentase \\
\hline \multirow{4}{*}{ LOTS } & Mengingat & Mengenali & 17 & $77.27 \%$ \\
& & Mengingat Kembali & 3 & $13.63 \%$ \\
\cline { 2 - 5 } & Memahami & Menafsirkan & 0 & $0 \%$ \\
& & Mencontohkan & 0 & $0 \%$ \\
& & Mengklasifikasikan & 0 & $0 \%$ \\
& & Merangkum & 0 & $0 \%$ \\
\hline
\end{tabular}




\begin{tabular}{lllll}
\hline & & Menyimpulkan & 0 & $0 \%$ \\
& & Membandingkan & 0 & $0 \%$ \\
& & Menjelaskan & 2 & $9.1 \%$ \\
\cline { 3 - 5 } & Mengaplikasikan & Mengeksekusi & 0 & $0 \%$ \\
& Menganalisis & Mengimplementasikan & 0 & $0 \%$ \\
& & Membedakan & 0 & $0 \%$ \\
& & Mengorganisasi & 0 & $0 \%$ \\
& Mengevaluasi & Mengatribusikan & 0 & $0 \%$ \\
\cline { 3 - 5 } & & Memeriksa & 0 & $0 \%$ \\
& Mencipta & Mengkritik & 0 & $0 \%$ \\
& & Merumuskan & 0 & $0 \%$ \\
& & Merencanakan & 0 & $0 \%$ \\
& & Memproduksi & 0 & $0 \%$ \\
\hline & TOTAL & & $\mathbf{2 2}$ & $\mathbf{1 0 0} \%$ \\
\hline
\end{tabular}

Berdasarkan tabel yang telah disajikan di atas, dalam proses pembelajaran Bahasa Indonesia pada awal pembelajaran diSMK Negeri 3 Soppengterdapat 22 pertanyaan guru yang muncul. Pertanyaan tersebut telah dikategorikan berdasarkan Taksonomi Bloom yang telah direvisi oleh Anderson dan Kratwhol dapat diuraikan sebagai berikut: pertanyaan mengenali sebanyak 17 pertanyaan (77.27\%), pertanyaan mengingat kembali sebanyak tiga pertanyaan (13.63\%), dan pertanyaan menjelaskan sebanyak dua pertanyaan (9.1\%). Hasil analisis data pertanyaan guru dengan kerangka LOTS HOTS menunjukkan bahwa 100\% pertanyaan tergolong Lower Order Thinking Skill(LOTS) dan 0\% tergolong Higher Order Thinking Skill (HOTS).

Tabel 2. Jumlah Pertanyaan Guru pada Inti Pembelajaran

\begin{tabular}{|c|c|c|c|c|}
\hline Ket. Berpikir & Proses Kognitif & Sub Aspek & Frekuensi & Persentase \\
\hline \multirow{11}{*}{ LOTS } & Mengingat & Mengenali & 22 & $20.56 \%$ \\
\hline & & Mengingat Kembali & 29 & $27.10 \%$ \\
\hline & Memahami & Menafsirkan & 0 & $0 \%$ \\
\hline & & Mencontohkan & 1 & $0.93 \%$ \\
\hline & & Mengklasifikasikan & 11 & $10.28 \%$ \\
\hline & & Merangkum & 0 & $0 \%$ \\
\hline & & Menyimpulkan & 0 & $0 \%$ \\
\hline & & Membandingkan & 0 & $0 \%$ \\
\hline & & Menjelaskan & 33 & $30.85 \%$ \\
\hline & Mengaplikasikan & Mengeksekusi & 0 & $0 \%$ \\
\hline & & Mengimplementasikan & 0 & $0 \%$ \\
\hline \multirow{8}{*}{ HOTS } & Menganalisis & Membedakan & 9 & $8.41 \%$ \\
\hline & & Mengorganisasi & 0 & $0 \%$ \\
\hline & & Mengatribusikan & 0 & $0 \%$ \\
\hline & Mengevaluasi & Memeriksa & 2 & $1.87 \%$ \\
\hline & & Mengkritik & 0 & $0 \%$ \\
\hline & Mencipta & Merumuskan & 0 & $0 \%$ \\
\hline & & Merencanakan & 0 & $0 \%$ \\
\hline & & Memproduksi & 0 & $0 \%$ \\
\hline \multicolumn{3}{|c|}{ TOTAL } & 107 & $100 \%$ \\
\hline
\end{tabular}


JURNAL BAHASA

2019, Vol 1(No 2), hlm. 111 - 121

https://jurnal.ppib-sip.id/index.php/bahasa

E-ISSN:

Berdasarkan tabel yang telah disajikan di atas, dalam proses pembelajaran Bahasa Indonesia pada inti pembelajaran di SMK Negeri 3 Soppeng terdapat 107 pertanyaan guru yang muncul. Pertanyaan tersebut telah dikategorikan berdasarkan Taksonomi Bloom yang telah direvisi oleh Anderson dan Kratwhol dapat diuraikan sebagai berikut: pertanyaan mengenali sebanyak 22 pertanyaan (20.56\%), pertanyaan mengingat kembali sebanyak 29 pertanyaan (27.10\%), pertanyaan mencontohkan sebanyak satu pertanyaan $(0.93 \%)$, pertanyaan mengklasifikasikan sebanyak 11 pertanyaan $(0.28 \%)$, pertanyaan menjelaskan sebanyak 33 pertanyaan $(30.85 \%)$, pertanyaan membedakan sebanyak 9 pertanyaan (8.41\%), pertanyaan memeriksa sebanyak dua pertanyaaan (1.87\%). Hasil analisis data pertanyaan guru dengan kerangka LOTS HOTS menunjukkan bahwa 89.72\% pertanyaan tergolong Lower Order Thinking Skill (LOTS) dan 10.28\% tergolong Higher Order Thinking Skill (HOTS).

Tabel 3. Jumlah Pertanyaan Guru pada Akhir Pembelajaran

\begin{tabular}{|c|c|c|c|c|}
\hline Ket. Berpikir & Proses Kognitif & Sub Aspek & Frekuensi & Persentase \\
\hline \multirow{11}{*}{ LOTS } & Mengingat & Mengenali & 4 & $19.04 \%$ \\
\hline & & Mengingat Kembali & 11 & $52.38 \%$ \\
\hline & Memahami & Menafsirkan & 0 & $0 \%$ \\
\hline & & Mencontohkan & 0 & $0 \%$ \\
\hline & & Mengklasifikasikan & 0 & $0 \%$ \\
\hline & & Merangkum & 0 & $0 \%$ \\
\hline & & Menyimpulkan & 0 & $0 \%$ \\
\hline & & Membandingkan & 0 & $0 \%$ \\
\hline & & Menjelaskan & 6 & $28.58 \%$ \\
\hline & Mengaplikasikan & Mengeksekusi & 0 & $0 \%$ \\
\hline & & Mengimplementasikan & 0 & $0 \%$ \\
\hline \multirow{8}{*}{ HOTS } & Menganalisis & Membedakan & 0 & $0 \%$ \\
\hline & & Mengorganisasi & 0 & $0 \%$ \\
\hline & & Mengatribusikan & 0 & $0 \%$ \\
\hline & Mengevaluasi & Memeriksa & 0 & $0 \%$ \\
\hline & & Mengkritik & 0 & $0 \%$ \\
\hline & Mencipta & Merumuskan & 0 & $0 \%$ \\
\hline & & Merencanakan & 0 & $0 \%$ \\
\hline & & Memproduksi & 0 & $0 \%$ \\
\hline \multicolumn{3}{|c|}{ TOTAL } & 21 & $100 \%$ \\
\hline
\end{tabular}

Berdasarkan tabel yang telah disajikan di atas, dalam proses pembelajaran Bahasa Indonesia pada akhir pembelajaran di SMK Negeri 3 Soppeng terdapat 21 pertanyaan guru yang muncul. Pertanyaan tersebut telah dikategorikan berdasarkan Taksonomi Bloom yang telah direvisi oleh Anderson dan Kratwhol dapat diuraikan sebagai berikut: pertanyaan mengenali sebanyak empat pertanyaan (19.04\%), pertanyaan mengingat kembali sebanyak 11 pertanyaan (52.38\%), dan pertanyaan menjelaskan sebanyak enam pertanyaan (28.58\%). Hasil analisis data pertanyaan guru dengan kerangka LOTS HOTS menunjukkan bahwa 100\% pertanyaan tergolong Lower Order Thinking Skill (LOTS) dan 0\% tergolong Higher Order Thinking Skill (HOTS). 


\section{Pembahasan}

Pertanyaan yang diajukan pada proses pembelajaran sangat penting bagi peserta didik. Pertanyaan yang berkualitas sangat mempengaruhi keberhasilan belajar peserta didik. Pada penelitian ini menunjukkan bahwa kadar pertanyaan tingkat tinggi yang diajukan guru pada proses pembelajaran Bahasa Indonesia sangatlah sedikit. Data yang diperoleh pada proses pembelajaran tersebut merupakan pertanyaan yang berada di dalam tataran mengingat yang termasuk kategori LOTS (Lower Order Thinking Skill). Namun kemampuan berpikir tingkat tinggi bukanlah kemampuan untuk mengingat, mengetahui, atau mengulang.

Peneliti menemukan bahwa pada bagian pembuka pembelajaran tidak terdapat pertanyaan tingkat tinggi. Seluruh pertanyaan yang diajukan pada awal pembelajaran merupakan pertanyaan yang dimaksudkan agar siswa menyiapkan dirinya untuk menerima materi pembelajaran yang akan dipelajari. Pada awal pembelajaran, guru mengajukan pertanyaan agar siswa menumbuhkan semangat dan motivasinya untuk mengikuti pembelajaran. Hal ini juga sejalan dengan Wahyupurnomo (2015) yang menyatakan bahwa keterampilan membuka pelajaran merupakan kegiatan dan pernyataan guru yang dilakukan pada pertama kali kegiatan pembelajaran dilaksanakan dengan tujuan untuk menciptakan suasana siap mental dan menimbulkan perhatian siswa agar terpusat pada hal-hal yang akan dipelajari.

Selanjutnya pada inti pembelajaran, penelitian ini menunjukkan bahwa guru hanya sesekali mengajukan pertanyaan tingkat tinggi.Frekuensi pertanyaan tingkat rendah lebih sering muncul dibandingkan dengan pertanyaan tingkat tinggi.Padahal inti pembelajaran merupakan bagian yang sangat tepat untuk mengajukan pertanyaan yang berkualitas.Aydin \& Yimas (dalam Fanani, 2018) menunjukkan bahwa guru harus memiliki pengetahuan dan keahlian untuk menunjang pekerjaannya, sehingga dapat mengembangkan keterampilan berpikir tingkat tinggi peserta didik.

Pada akhir pembelajaran, penelitian ini menujukkan bahwa guru cenderung memberikan pertanyaan tingkat rendah. Guru tidak pernah mengajukan pertanyaan tingkat tinggi pada akhir pembelajaran. Hal ini dikarenakan, pada awal pembelajaran guru lebih cenderung merangkum materi pembelajaran yang telah diajarkan. Hal ini juga sejalan dengan Wahyupurnomo (2015) menutup pelajarandimaksudkan untuk memberi gambaran menyeluruh tentang apa yang telah dipelajari siswa, serta mengetahui tingkat pencapaian anak didik dan tingkat keberhasilan guru dalam proses pembelajaran.Pada akhir pembelajaran, guru juga kerap menanyakan kehadiran siswa pada pertemuan tersebut, sesekali juga guru menanyakan ketuntasan nilai siswa pada mata pelajaran tersebut.

Rosnawati (dalam Fanani, 2018) menjelaskan kemampuan berpikir tingkat tinggi dapat terjadi ketika seseorang mengaitkan informasi yang baru diterima dengan informasi yang sudah tersimpan di dalam ingatannya, kemudian menghubung-hubungkannya dan/atau menata ulang serta mengembangkan informasi tersebut sehingga tercapai suatu tujuan ataupun suatu penyelesaian dari suatu keadaan yang sulit dipecahkan. Namun demikian, pertanyaan yang muncul pada proses pembelajaran Bahasa Indonesia di SMKN 3 Soppeng ini yang muncul hanya pertanyaan yang tidak dapat dihubung-hubungkan dan tidak dapat dikembangkan. Pertanyaan yang sering muncul adalah pertanyaan mengarahkan menuntut, yaitu pertanyaan yang diajukan untuk memberi arah kepada murid dalam proses berpikirnya (Ningsih, 2014).

Keterampilan bertanya di dalam proses pembelajaran sangat mendukung kualitas pembelajaran, baik pertanyaan yang diajukan seorang guru maupun pertanyaan yang diajukan seorang siswa. Pertanyaan pada proses pembelajaran sangat mendukung keberhasilan suatu pembelajaran. Dalam hal ini pertanyaan yang berkualitas.

Implementasi HOTS (Highter Order Thingking Skill) sangat minim untuk dikembangkan jika diterapkan melalui pertanyaan pada proses pembelajaran. Hal ini dapat dilihat karakteristik HOTS sebagaimana diungkapkan oleh Resnick (dalam Fanani, 2018) diantaranya adalah non algoritmik, bersifat kompleks, multiple solutions (banyak solusi), melibatkan variasi pengambilan keputusan dan 
JURNAL BAHASA

2019, Vol 1(No 2), hlm. 111 - 121

https://jurnal.ppib-sip.id/index.php/bahasa

E-ISSN:

interpretasi, penerapan multiple criteria (banyak kriteria), dan bersifat effortful (membutuhkan banyak usaha). Karakteristik tersebut diatas sangat susah diterapkan pada pertanyaan-pertanyaan dalam proses pembelajaran. Hal inilah yang menunjukkan bahwa proses berpikir tingkat tinggi melalui pertanyaan pada proses bembelajaran sangat susah untuk dikembangkan.

Kemampuan guru dalam mengajukan pertanyaan ditinjau dari dua aspek, yaitu jenis pertanyaan yang diajukan dan teknik guru dalam mengajukan pertanyaan tersebut.Guru benar-benar memprioritaskan memberikan pertanyaan yang pada tingkat recall. Proses kognitif untuk mengingat, memahami, dan menerapkan dimensi dikelompokkan dalam proses kognitif tingkat rendah (Hamsah dan Sultan, 2014).Pertanyaan diajukan hanya untuk mengetahui penguasaan siswa terhadap materi pelajaran. Selain itu, sedikitnya pertanyaan kognitif tingkat tinggi yang diajukan guru juga disebabkan karena guru tidak merencanakan pertanyaan-pertanyaan yang akan diajukannya.

Hasil penelitian ini menunjukkan bahwa pertanyaan yang diajukan guru pada proses pembelajaran Bahasa Indonesia yaitu awal, tengah dan akhir pembelajaran merupakan pertanyaan tingkat rendah. Hasil tersebut sejalan dengan penelitian Novarina (2015) yang meneliti tentang jenisjenis pertanyaan yang diajukan guru berdasarkan Taksonomi Bloom dalam kegiatan pendahuluan, inti dan penutup pada pembelajaran matematika kelas X SMA Negeri 1 Purworejomenemukan bahwa pada proses pembelajaran lebih didominasi pertanyaan pengetahuan, guru hanya sesekali mengajukan pertanyaan sintesis dan evaluasi.

Hal ini juga serupa dengan Widjaya, dkk (2013) yangmeneliti tentang analisis pertanyaan guru dalam proses pembelajaranBahasa Indonesia pada Siswa Kelas V Sekolah DasarNegeri 3 Selong Lombok Timur Nusa Tenggara BaratTahun Pembelajaran 2012/2013Tingkatan Kognitif Pertanyaan Guru Kelas V SD Negeri 3 Selong, Lombok Timur, Nusa Tenggara Barat yang menemukan bahwa dalam proses pembelajaran bahasa Indonesia sudah mencapai keenam tingkatan kognitif Taksonomi Bloom. Apabila dilihat dari sebarannya, pertanyaan guru terfokus pada dua tingkatan berpikir rendah yaitu pengetahuan dan pemahaman. Hal ini menunjukkan bahwa guru kurang mampu memanfaatkan pertanyaan untuk menumbuhkembangkan daya pikir kritis dan kreatif siswa dalam memecahkan masalah. Dengan pertanyaan pengetahuan dan pemahaman guru kurang mampu membuat siswa untuk menggunakan bahasa Indonesia sebagai alat berpikir tingkat tinggi.Tiga penelitian tersebut diatas menunjukkan bahwa keterampilan berpikir tingkat tinggi sangat susah dikembangkan melalui pertanyaan-pertanyaan pada proses pembelajaran.

Pertanyaan kognitif tingkat tinggi tidak dapat diajukan secara spontan melainkan harus direncanakan.Pertanyaan yang memiliki kualitas yang baik harus direncanakan terlebih dahulu.Guru hendaknya mengikuti pelatihan-pelatihan dalam mengembangkan kemampuan pedagogiknya dalam memberikan pertanyaan dalam sebuah pembelajaran, mengikuti pelatihan-peltihan untuk mampu mengembangkan soal-soal HOTS dalam proses pembelajaran. Guru juga harus mampu mengolah pembelajaran dengan baik agar keterampilan berpikir siswa dapat berkembang. Kemudian untuk implikasinya bagi pembelajaran Bahasa Indonesia, guru hendaknya menggunakan metode pembelajaran yang dapat menunjang atau melatih kemampuan berpikir kritis dan melatih keaktifan peserta didik dalam proses pembelajaran. Keaktifan peserta didik pada proses pembelajaran dapat menentukan keberhasilan seorang guru maupun siswa dalam sebuah pembelajaran. Tentunya juga pembiasaan bagi guru untuk selalu mengajukan pertanyaan dalam proses pembelajaran baik pada bagian awal, tengah, maupun akhir pembelajaran sehingga dapat melatih kemampuan peserta didik dalam proses kognitifnya. 


\section{Penutup}

Pada awal pembelajaran Bahasa Indonesia di SMK Negeri 3 Soppeng terdapat 22 pertanyaan guru yang muncul.Pertanyaan mengenali sebanyak 17 pertanyaan $(77.27 \%)$, pertanyaan mengingat kembali sebanyak tiga pertanyaan (13.63\%), dan pertanyaan menjelaskan sebanyak dua pertanyaan (9.1\%). Hasil analisis data pertanyaan guru dengan kerangka LOTS HOTS menunjukkan bahwa $100 \%$ pertanyaan tergolong Lower Order Thinking Skill (LOTS) dan 0\% tergolong Higher Order Thinking Skill (HOTS).

Pada inti pembelajaran Bahasa Indonesia di SMK Negeri 3 Soppeng terdapat 107 pertanyaan guru yang muncul. Pertanyaan mengenali sebanyak 22 pertanyaan $(20.56 \%)$, pertanyaan mengingat kembali sebanyak 29 pertanyaan (27.10\%), pertanyaan mencontohkan sebanyak satu pertanyaan $(0.93 \%)$, pertanyaan mengklasifikasikan sebanyak 11 pertanyaan $(0.28 \%)$, pertanyaan menjelaskan sebanyak 33 pertanyaan (30.85\%), pertanyaan membedakan sebanyak 9 pertanyaan $(8.41 \%)$, pertanyaan memeriksa sebanyak dua pertanyaaan (1.87\%). Hasil analisis data pertanyaan guru dengan kerangka LOTS HOTS menunjukkan bahwa $89.72 \%$ pertanyaan tergolong Lower Order Thinking Skill (LOTS) dan 10.28\% tergolong Higher Order Thinking Skill (HOTS).

Pada akhir pembelajaran Bahasa Indonesia di SMK Negeri 3 Soppeng terdapat 21 pertanyaan guru yang muncul.Pertanyaan mengenali sebanyak empat pertanyaan (19.04\%), pertanyaan mengingat kembali sebanyak 11 pertanyaan (52.38\%), dan pertanyaan menjelaskan sebanyak enam pertanyaan (28.58\%). Hasil analisis data pertanyaan guru dengan kerangka LOTS HOTS menunjukkan bahwa 100\% pertanyaan tergolong Lower Order Thinking Skill (LOTS) dan 0\% tergolong Higher Order Thinking Skill (HOTS).Berdasarkan temuan, guru direkomendasikan memanfaatan pertanyaan tingkat tinggi dalam proses pembelajaran. Dengan pertanyaan yang berkualitas, maka akan proses berpikir kritis dan kreatif seorang siswa.

\section{Ucapan Terima Kasih}

Penulis mengucapkan terima kasih kepada mitra bestari (reviewers) yang telah memberikan saran, kritikan dan perbaikan terhadap naskah ini.Komentar dan rekomendasi yang diberikan telah membantu penulis untuk meningkatkan kualitas artikel ini.

\section{Daftar Pustaka}

Auzar, dkk. (2015).Pertanyaan Yang Diajukan GuruDalam Proses Pembelajaran Bahasa Indonesia Di SMA Negeri 10 Pekanbaru. Jurnal Bahasa, 10 (1): 23-30.

Astuti, dkk. (2017).Identifikasi Kemampuan Bertanya Dan Berpendapat CalonGuru Biologi Pada Mata Kuliah Fisiologi Hewan. Bioesukasi, 15 (1): 24-31.

OECD. (2010). PISA 2009 Results: Executive Summary. New York: Columbia University OECD. (2013). PISA 2012 Results in Focus: What 15year-olds know and what they can do with what they know. New York: Columbia University.

OECD.(2015). PISA 2015 Draft Mathematics Framework. New York: Columbia University OECD. (2016).

PISA (2015) Results in Focus. New York: Columbia University

Hamsa, Akmal., dan Sultan. (2014). Interogasi di Interaksi Guru-Siswa dalam Bahasalndonesia Belajar di Sekolah Dasar.Jurnal Pendidikan dan Pembelajaran, 8 (3): 249-256.

Julianingsih, Suhaeti. (2017). Skripsi. Pengembangan Instrumen Asesmen Higher OrderThinking Skill (Hots) untuk Mengukur DimensiPengetahuan IPA Siswa di SMP.Skripsi. Bandarlampung: Fakultas Keguruan dan Ilmu Pendidikan Universitas Lampung. 
JURNAL BAHASA

2019, Vol 1(No 2), hlm. 111 - 121

https://jurnal.ppib-sip.id/index.php/bahasa

E-ISSN:

Nurhayati, Angreni Lia. (2017). Analisis Kemampuan Berpikir Tingkat Tinggi Mahasiswa (Higher Order Thinking) dalam Menyelesaikan Soal Konsep Optika melalui Model Problem Based Learning. Jurnal Penelitian \& Pengembangan Pendidikan Fisika, 3 (2): 119-126.

Nurmadinah. (2017). Pengembangan Instrumen Tes Higher Order Thinking Skill (Hots) Pokok Bahasan Operasi Hitung Bentuk Aljabar Serta Persamaan Dan Pertidaksamaan Linear Satu Variabel Kelas VII MTS Guppi Samata. Skripsi. Makassar: Fakultas Tarbiyah dan Keguruan Universitas Islam Negeri Alaudin.

Novriana, Eka dan Imam Sujadi. (2015). Analisis Jenis-Jenis Pertanyaan yang Diajukan Guru Berdasarkan Taksonomi Bloom dalam Kegiatan Pembelajara Matematika Kelas X Di SMA Negeri 1 Purworejo.Prosiding Seminar Nasional Matematika dan Pendidikan Matematika.

Purwanto. (2009). Evaluasi Hasil Belajar. Yogyakarta: Pustaka Belajar.

Risovi, Zulhani. (2014). Keterampilan Bertanya Guru dalam Meningkatkan Aktivitas Belajar Siswa pada Mata Pelajaran Fiqih. Skripsi.Jakarta: Fakultas IImu Tarbiyah dan Keguruan Universitas Islam Negeri Syarif Hidayatullah.

Supratna, Eka dan Muhammad Arif Wahyupurnomo. (2015).Keterampilan Guru dalam Membuka dan Menutup Pelajaran Pendidikan Jasmani Olahraga dan Kesehatan di SMAN Se-kota Pontianak.Jurnal Pendidikan Jasmani Indonesia, 11(1): 66-71.

Waybin, Eusabia Floreza. (2014). Implementasi Kurikulum 2013 Dalam Proses Pembelajaran di SMK Negeri 3 Yogyakarta. Skripsi. Yogyakarta: Fakultas Teknik Universitas Negeri Yogyakarta.

Widjaya, dkk. (2013).Analisis Pertanyaan Guru dalam Proses Pembelajaran Bahasa Indonesia pada Siswa Kelas V Sekolah Dasar Negeri 3 Selong Lombok Timur Nusa Tenggara BaratTahun Pembelajaran 2012/2013.e-Journal Program Pascasarjana Universitas Pendidikan Ganesha Program Studi Pendidikan Bahasa dan Sastra Indonesia, 2. 